\title{
Evaluation of Country Awareness Program Development through Education and Training
}

\author{
Deni Dadang Ahmad Rajab*, Billy Tunas, Widodo Sunaryo \\ Pakuan University, Bogor, Indonesia
}

*Corresponding Author: Deni Dadang Ahmad Rajab, Pakuan University, Bogor, Indonesia

\begin{abstract}
State Defending Awareness Guidance is a national program to build awareness of Indonesian citizens to carry out their rights and obligations in the defense of the state following the mandate of the 1945 Constitution. The Indonesian Ministry of Defense is the leading sector in the training of Country Awareness Training. Since the founding of the organization, no academic evaluation has been carried out to see the effectiveness and efficiency of the Country Awareness Development Program through the training method. This study was prepared using a qualitative method, an evaluation approach with the CIPP (Context, Input, Process, and Product). In this study, there were four components, 22 sub-components, and 66 criteria were evaluated.The results showed that 16 of the 66 evaluation criteria had not yet been achieved, namely: 1) Carrying out a need assessment of solutions and opportunities for cadre formation; having a vision that is 2) focused, 3) measurable, and mission that is 4) focused; 5) SMART objectives (Specific, Measurable, Achievable, Realistic, and Time bound); 6) has a cadre juridical foundation; 7) refers to the curriculum guidelines for the state defense education and training center of the Ministry of Defense; 8) has a library, the recruitment of educators has a basis in the form of guidelines that explain; 9) policy; 10) procedure; 11) the implementation of recruitment of educators according to guidelines and planning; 12) achievement of the List of Personnel Arrangement at the Center for Education and Training of State Defending, conducting evaluations in accordance with the guidelines; 13) evaluating the implementation of education and training; 14) evaluation of learning outcomes; 15) there is a list of values as a cadre learning document; and 16) there are regulations regarding the use of state defense cadres for the socialization of Country Awareness Program.The study concludes that the Country Awareness Program through the Training of State Defending in the Center for Education and Training of the Indonesian Ministry of Defense is recommended to be continued by realizing the criteria that have not yet been achieved.
\end{abstract}

Key words: program evaluation, , council awareness development, defense, training,

\section{INTRODUCTION}

The national defense system is a system that is held to maintain the sovereignty, territorial integrity, and safety of the nation and state from various threats involving all Indonesian citizens and national resources. Law Number 3 of 2002 Article 1 paragraph (2) explains that the national defense system is prepared in advance by the government in a total, integrated, directed and sustainable manner. Development of a unified national defense system, consisting of military defense and non-military defense which is directed to synergize and improve the effectiveness and efficiency of coordination in the administration of national defense in the face of the military, non-military and hybrid threats.

Nation Character Building as part of the mental revolution program is carried out through fostering awareness and ability to defend the state for every Indonesian citizen in a residential, educational and work environment, one of which is through the activities of forming a national defense cadre by including citizens in the effort to defend the state which is held through civic education, compulsory military basic training, voluntary or mandatory service as a soldier, and service according to the profession.

Based on the facts and results of the preliminary survey, it is necessary to have an academic evaluation to overcome the problems of education and training management in the Center for Education and Training of the Indonesian Ministry of Defense. This is very important to do considering management is a process to achieve goals. In addition, the Center for Education and Training for the State Defense was formed as a leading sector in the implementation of education and 
training so that it would be used as a benchmark in the implementation of state defense training for all Ministries / Institutions / Agencies in Indonesia.

The main problem formulation of this research focuses on How to evaluate the Country Awareness Development Program through state defense training at the Center for Education and Training of the Ministry of Defense? To answer these key questions, the research questions are detailed as follows:

1. How is the process of determining the basics of forming an organization through a. Need Assessment Organizational, b. Vision and Mission of the Organization, c. Organizational Objectives, d. Organizational Goals, and e. Juridical Foundation Organization of the Center for Education and Training of the Ministry of Defense?

2. How is the planning and preparation of the program which includes: a. Organizational Structure, b. Organizational Strategy, c. State Defense Training and Education Curriculum, d. Education and Training Activities Plan, e. Facilities and Infrastructure, f. Procedure for Recruitment of Education and Training Personnel, g. Training Procedure for Recruitment of Training Participants, h. Supervision and control system and i. Education and Training Evaluation System at the Center for Education and Training of the Ministry of Defense?

3. How is the compatibility between the implementation with the education and training plan, which consists of a. Implementation of Recruitment of Training Personnel, b. Implementation of Training Participants Recruitment, c. Implementation of Activities, d. HR availability, e. Implementation of Supervision and control, and f. Conducting Evaluation at the Center for Education and Training of the Martial Arts Center for Education and Training of the Ministry of Defense?

4. What are the results (outputs) and impacts (outcomes) that show the benefits of the State Defending Awareness Program through Education and Training at the Center for Education and Training of the Ministry of Defense?

\section{LITERATURE REVIEW}

\section{A. Program Evaluation Concept Program}

Evaluation is part of management in an organization's management system that is oriented towards implementing policies that have been designed by an organization through programs. According to Stufflebeam (2017), program evaluation is an effort to find out the level of implementation of a policy carefully by knowing the effectiveness of each component. Program evaluation is an activity that is included in the management agenda of an organization and becomes a component in the system. Zhang (2011) explains that program evaluation efforts are included in a systematic method for gathering, analyzing and using the information to answer basic questions about the program. In line with this opinion, Hakan (2011) states that program evaluation is a systematic activity to collect, process, analyze and present data as input for decision making.

Based on the opinion above, it can be synthesized that program evaluation is a systematic activity to obtain data and information regarding the suitability of the program that has been designed with the implementation that has been carried out so that an alternative for further policies is obtained in determining a better program.

\section{B. CIPP Evaluation Model}

Stufflebeam (2017) explains that the CIPP model is based on learning by doing that is, an ongoing effort to identify and correct mistakes made in evaluation practice, to invent and test needed new procedures, and to retain an incorporate especially effective practices. The CIPP model is based on learning by doing, that is, ongoing efforts to identify and correct mistakes made in the evaluation program, to create and test new procedures needed, and to maintain or continue effective practices.

Zhang (2011) ) explains theCIPP evaluation model is designed to systematically guide both evaluators and stakeholders in posing relevant questions and conducting assessments at the beginning of a project (Context and Input evaluation), while it is in progress (Input and Process evaluation), and at its end (product evaluation). This means that theevaluation model is CIPP designed systematically as a guide for evaluators and stakeholders in asking relevant questions and conducting initial project 
assessments (context and input evaluation), while it is ongoing (Inputs and processes), and at the end (products).

Hakan (2011) explain that One of the strengths of the CIPP model is, especially, that it is a useful and simple tool for helping evaluators produce questions of vital importance to be asked in an evaluation process. Evaluators can determine lots of questions for each component of the CIPP model. This means that one of the strengths of the CIPP model is that, as a simple but useful tool for evaluators to generate important questions to ask the evaluation process. The evaluator can determine many questions for each component of the CIPP model.

\section{a.(Context Evaluation)}

The Context evaluation component addresses the goal identification stage of a service-learning project. An effective service-learning project starts with identifying the needs of service providers (students) and the needs of the community. This means that the context evaluation component is directed at the stage of identifying the learning service project objectives. An effective service project starts with identifying the needs of the service provider (students) and the needs of the community. The context evaluation also aims to assess whether the goals and priorities that have been set to meet the needs of the parties being targeted by the organization (Tunc,2010).

\section{b.Evaluation Input}

The input evaluation component can then help prescribe a responsive project that can best address the identified needs, and evaluation component input determines the project is the responsive best lead to the identification needs.

\section{c.Evaluation Process}

Stufflebeam (2017) states that In Process evaluations, the Evaluators monitor, document, study and report on the application of program plans. These evaluators make feedback in the Implementation Process of a program, and upon completion of the program, report on the continuation of the program as targeted and required.In the evaluation process, evaluators monitor, document, research and report on the implementation of program planning. The evaluator provides input into the program implementation process, after the program finishes, reports the sustainability of the program as targeted and needed.

\section{d.Product Evaluation}

According to Hakan (2011), the outcome is a product of the collection of descriptions and numerous archived judgments about the objectives, merit, and worth of theprogram. The outcome is the product of a set of descriptions and a number of assessments about the programme's goals, achievements, and benefits.

Rajiani (2010) explains that the purpose of product evaluation is to measure, interpret, and judge an enterprise's outcome. Its main objective is to ascertain the extent to the Evaluation and the net needs of all rightful beneficiaries. The purpose of product evaluation is to measure, interpret, and assess the results of the company (organization). The main objective is to ensure the extent to which the program being evaluated meets the needs of all rightful recipients.

\section{The Concept of Defending the State}

Cheng (2010) explains that the defense of the state is the attitudes and actions of citizens based on a sense of patriotism, national and state awareness.National Principle beliefs as an ideology of the nation and state, willingness to sacrifice to face many threats, challenges, obstacles and disturbances both coming from within and from outside that endanger the survival of the nation and the State, territorial integrity, national jurisdiction and noble values of the National Principle and the 1945 Constitution. In line with the previous opinion, Riseman (2012) explained that the effort to defend the country could be carried out by all people through devotion in accordance with their profession which in essence acts of state defense is an effort of citizens to realize national resilience.

In the book Study on the Need for a Non-Military Defense Strategy, it is explained that there are five basic attitudes in defending the State, namely: 1) the love of the motherland to defend the Unitary Republic of Indonesia; (2) national and state awareness in diversity; (3) believe in National Principle as the ideology and philosophy of the nation; (4) willing to sacrifice for the homeland and nation; and 
(5) has the initial ability to defend the state which includes physical and psychological abilities (Rajiani,2010).

\section{MethodS}

The evaluation model used in this study is the CIPP model, namely, Context, Input, Process, and Product. As for the program evaluated in this education, it is the State Defense training program that is carried out at the Center for Education and Training for the Ministry of Defense. The data analysis technique used in this research is descriptive qualitative. Basically, the descriptive analysis is to hold a hospitalization for a situation, also determine the frequency of occurrence of an event, with or without a hypothesis. This analysis refers to the model of Miles and Hubermanwhich explains that there are three stages that must be carried out in data analysis, namely data reduction, data display, and conclusion: drawing and verifying (drawing conclusions/verification).

\section{RESUltS AND DisCuSSION}

\section{A.Discussion Component Evaluation Context}

The activity needs assessment is a very important first step to be done in determining the direction of the organization based on the needs of current and future. This is in line with Stufflebeam (2017) that an evaluator uses context evaluation to assess needs, problems, assets, and opportunities in a given evaluation. These needs are things that are needed or useful to meet the objectives that can be maintained. Evaluation results indicate the criteria achieved in the sub-component need assessment, namely: a. Conduct gap analysis, b. identify priorities; c. identify the causes of performance problems and or opportunities. Meanwhile, the evaluation criteria that have not yet been achieved are identifying solutions and or growth opportunities for cadre formation that have not been carried out in-depth because they do not discuss the use of outputs (cadres) that have implemented training so that the State Defense Cadre from the Center for Education and Training Defense can be utilized to assist the government in realizing national programs to foster awareness of the defense of the state both in the educational, residential, and occupational environments as a form of devotion to the State and Nation.

In order to strengthen the picture of the future, an ideal vision and mission are needed, as stated by Ho (2011) that vision is the future condition of the company to be realized. The function of the vision is to direct the company's journey towards the future so that the vision of the vision must be clear with the trend of environmental change. Based on the above theory and the results obtained, the organizational vision criteria of the Center for Education and Training of the Ministry of Defense in this study are interesting but has not fulfilled the other two aspects, namely realistic and measurable. The evaluation results show the criteria that have been achieved in the vision are interesting; the criteria that have been achieved in the mission are simple and concise. While the criteria that have not been achieved in the vision are not measurable and have not been focused on the future, the criteria that have not been achieved in the mission are not yet focused. Vision is a picture of the future that explains the needs, while the mission describes the organization's steps to achieve the vision based on available resources so that it is known opportunities, challenges, problems, and solutions to meet those needs.

Bowman (2015) explains that the formulation of good goals includes five criteria, namely Specific, Measurable, Achievable, Realistic, and Timebound. The evaluation results indicate the criteria of organizational objectives achieved subcomponent is formulated objectives State Defense Training Program as a translation of the vision and mission specific. The criteria that have not been reached are Measurable, Achievable, Realistic, and Timebound. The purpose of the Center for Education and Training of the National Defense Center The Ministry of Defense's Education and Training Center uses the purpose of Council Awareness Development in Ministry of Defense Decreat number 32/2016 as the goal of the organization. It is necessary to have organizational goals that are tailored to the organization's vision and mission so that the goals can be adjusted to the needs and budget and become specific, measurable, achievable, realistic, and timelines.

The Center for Education and Training of the Martial Arts The Ministry of Defense's Education and Training Center has three targets namely performance targets listed in the Main Performance Indicators manuscripts, work program targets listed in the work program and budget texts, and training objectives listed in the training curriculum. These targets have a period of one year each work 
program that is adjusted to the objectives of the Defense of State Defending Awareness. The results showed that the Ministry of Defense's State Defender Education and Training Center target could be continued and developed. Evaluation results show that all evaluation criteria in the sub-component of the organization's objectives have been achieved, namely a. is a translation of the objectives and $b$. have a period of time. Widodo (2015: 66) explains that the goal is a translation of the objectives and in the form of short-term goals for a period of 1 month to 12 months.

\section{B.Discussion of Input Evaluation Components}

The results of the Evaluation of all the criteria in the sub-component of the organizational Structure have been achieved, namely a. The organizational structure is formed on the basis of a clear legal basis and b. Explain the existence of Collaboration, HR, and common goals. The organizational Structure explains the tasks, functions, and coordination between organizational elements formally and legally. This is in line with Riseman (2012) explanation that organization is a process of collaboration between two or more people to achieve common goals effectively and efficiently. This definition implies that the organization has three components, namely: a. there is cooperation, b. there are people and c. there is a common goal.

The evaluation results showed that all the criteria in the sub-component of the education and training strategy had been achieved; namely, the Education and Training Center at the Center for Education and Training of the Ministry of Defense's Education and Training Ministry of Defense was implemented with a facilitation strategy. The facilitation strategy used was considered appropriate, considering the training of state defense at the Center for Education and Training of the Martial Arts. The Center for Education and Training of the Ministry of Defense was held to achieve the goal of social change in the field of national defense by raising awareness of the importance of making efforts to defend the country by each citizen through their respective expertise. The strategy patterns used are design, awareness and attention, Evaluation, and experiment. Implementation of social change programs using facilitative strategies means to achieve predetermined social change goals, preferably providing facilities with the intention that social change programs will run easily and smoothly.

The evaluation results show the criteria that have been achieved in the curriculum sub-component of the training, namely a. relevant to the development of society, science and technology and the needs of national defense to face non-military threats. The criteria that have not yet been reached are $b$. The curriculum at the Ministry of Defense Education and Training Center of the Ministry of Defense's Education and Training Center has not yet fully referred to the Ministry of Defense's Ministry of Defense Education and Training curriculum.

Evaluation results show that all evaluation criteria in the sub-component of the activity plan have been achieved, namely a. Explain training activities to be carried out at the Center for Education and Training of the National Defense Training and Education Center for the Ministry of Defense, $b$. Explain planned training activities to be carried out, c. Contains information on the results to be achieved from the implementation of the education and training centre by the Ministry of Defense Education and Training Center for the Ministry of Education and Training, and d. Contains information on the planned Time for education and training in the Center for Education and Training of the Martial Arts Education and Training Center of the Ministry of Defense.

Evaluation results show the evaluation criteria that have been achieved in the sub-component recruitment procedures for educators are (1) There are guidelines that explain the qualifications / requirements to become educators, two other criteria that have not been achieved namely (2) There are guidelines that explain the Policy recruitment of teaching staff and (3) There are guidelines that explain the recruitment procedures of teaching staff.

The evaluation results show that all the criteria in the sub-component of the Training and Education Cadre Recruitment Procedure have been achieved, namely the existence of guidelines containing procedures, policies, systems, and requirements of students. Even though defending the country is the right and obligation of every Indonesian citizen, but to be able to produce a National Defending Cadre quality and professional recruitment and selection are needed. Therefore, so that recruitment activities can be carried out systematically, it is important for an institution to draw up recruitment guidelines that explain the stages of implementation, criteria, and procedures for student recruitment. 
The evaluation results show all evaluation criteria in the Supervision and Control sub-component (Supervision and control) has been achieved, namely the existence of guidelines for supervision and control related to the implementation of work programs and budgets that explain: a. time, b. performance indicators, c. financing, d. procedures for the implementation of supervision and control and e) Implementation of training that explains the procedures for implementing supervision and control.

Evaluation results show that all evaluation criteria in the evaluation system sub-component have been achieved, namely: there are guidelines that contain procedures and indicators: a. evaluation of work programs and budgets, b. Evaluation of the Implementation of Education and Training, and c. Evaluation of Learning Outcomes.

\section{C.Discussion on the Process Evaluation Component}

Based on the research findings in the training component sub-component of education and training personnel, it is known that the implementation of recruitment still refers to the SOP for determining personnel positions in the Ministry of Defense conducted through a closed selection system by considering ranks through activities carried out by relevant officials. Therefore, it is necessary to formulate a derivative SOP related to the recruitment of training personnel in the Center for Education and Training of the Ministry of Defense's Ministry of Education and Training. The SOP is part of planning that can increase the accountability of organizational management in meeting the needs of training staff.

Evaluation results show that the Training Participant Recruitment Implementation has fulfilled all evaluation criteria a. Carry out recruitment according to the recruitment plan and $b$. There is Training Participant data. The recruitment of training participants is in accordance with the guidelines containing policies, selection systems, criteria, and procedures for acceptance of training participants who have been determined. This is in accordance with the presentation of Tunc (2010) that the acceptance of students includes the determination of policies, systems, criteria, and procedures for student acceptance.

The results showed that all the criteria in the sub-component of the implementation of the activities had been achieved namely a. Implementation of the Work Program in accordance with planning, $b$. Implementation of Operational Training and Education in the Center for Education and Training of the State Defense Education and Training Center of the Ministry of Defense in accordance with the plan, c. There is a text of the report on the implementation of the work program, and d. There is a text of the report on the implementation of education and training.

The research findings show that the evaluation criteria fulfilled in the HR availability subcomponent are the fulfilment of the target (number) of training participants. The evaluation criteria that have not been met is the non-fulfilment of the List of Personnel Composition at the Center for Education and Training of the Ministry of Defense.Rajaini (2010) explained that human resources in the context of education are grouped into human resources of education personnel consisting of educators or education staff and administrative staff. The findings of the study explain that the Center for National Defense Education and Training lacks Trainers and Education Personnel to fill in the formation according to the Personnel Compilation Data, their main tasks and professionalism.

The research findings show that all evaluation criteria in the sub-component of the implementation of supervision and control in the Center for Education and Training of the National Defense Training and Education Center of the Ministry of Defense have been achieved, namely a. Implementation of supervision and control of work programs and budgets in accordance with the guidelines, $b$. Implementation of Supervision and control of Education and Training in accordance with the guidelines, c. There are reports on the implementation of supervision and control of work programs and budgets that contain corrective feedback and follow-up, and d. There is a report on the implementation of education and training that contains feedback and corrective follow-up. Supervision and control (supervision and control) in an organization is carried out in order to improve the organization to carry out programs in accordance with the targets to be achieved. Evaluation of Work Program and Budget Implementation is an annual evaluation made at the end of the program implementation year. It includes an analysis and evaluation of the achievement of work program targets, as well as analysis and Evaluation of budget support 


\section{D.Discussion of Product Evaluation Components Evaluation}

criteria in the sub-components output are a. the existence of graduates of education and training in accordance with the targeted number and $b$. the existence of cadre learning outcomes that show the achievement of learning outcomes in the realm of cognitive (intellectual), affective (values and attitudes), and psychomotor (behavior) that shows awareness of defending the country. The training program of Country Awareness Training and Training carried out by the Center for National Defense Education and Training is held to meet the needs of national defense in order to increase deterrence by building the capacity of knowledge of defense human resources (Indonesian citizens) about their rights, obligations and roles to defend the country. Based on this, the benchmarks of training success are cadre learning outcomes that show the achievement of indicators of learning outcomes in the cognitive (knowledge), affective (attitude), and psychomotor (behavioral) domains. There need to be improvements made by the Ministry of Defense Education and Training Center of the Ministry of Defense's Education and Training Center, especially in carrying out Evaluation of learning outcomes and archiving. This is very important, because the success of an educational organization is not only seen from the success of organizing the program but how the program can produce graduates who can be used because of certain needs.

Evaluation results indicate the evaluation criteria achieved in the sub-component of outcomes, namely the benefits for cadres and users. The evaluation criteria that have not yet been achieved are the benefits for the state in the context of the Dissemination of the Promotion of Defending State Awareness. Fostering State Defending Awareness through education and training at the Center for Defense and Training of the State Defense Education and Training Center of the Ministry of Defense aims to support the achievement of the vision and mission of Fostering State Defender Awareness in accordance with Minister of Defense Regulation Number 32 the Year 2016 concerning Guidelines for Guiding National Defense Awareness, namely the formation of defensive power in facing nonmilitary threats with the vision of "the realization of Indonesian Citizens who have the Defense and Awareness of the State Defense, and mission: a. realizing Indonesian citizens who have the attitude and mental character of defending the country, and b. Build the character of every citizen so that they have a love of the motherland and national and state awareness, are loyal to National Principle as the state ideology, are willing to sacrifice for the homeland, nation and state, and have the initial ability to defend the country both physically, psychologically, and mentally.

The benefits of state defense training at the Center for Education and Training of the State Defense Education and Training Center of the Ministry of Defense of the Republic of Indonesia are felt directly by the cadres and users of these cadres both from the educational environment, work environment, and residential environment. However, it should be noted that the allocation of the Martial Arts Awareness Development program through the Education and Training Center for the National Defense Training and Training Center for the Ministry of Defense is not solely to implement the mandate of the Act requiring the defense of the state to be carried out by each citizen as rights and obligations, but the results of the country's defense activities must have an impact on the country to strengthen the country's defense against non-military threats. The cadres of the state defense education and training centre of the Ministry of Education and Training of the Ministry of Defense's Education and Training Center are required to provide benefits to the state, especially in the context of socializing the implementation of Country Awareness Development.

\section{CONCLUSION}

Based on the results of research and discussion, it is known that in general the Defending State Awareness Program through Education and Training at the Center for Education and Training of the Ministry of Defense's Ministry of Education and Training is held in the good category, meaning that most of the evaluation criteria are achieved. It is therefore recommended that the Martial Arts Awareness Development Program through the Martial Arts Training in the Center for Education and Training of the State Defense Education and Training Center of the Ministry of Defense of the Republic of Indonesia continue to be continued and improved.

\section{REFERENCES}

[1] Bowman, J., Mogensen, L., Marsland, E., \& Lannin, N. (2015). The development, content validity and inter-rater reliability of the SMART-Goal Evaluation Method: A standardized method for evaluating clinical goals. Australian occupational therapy journal, 62(6), 420-427. 
[2] Chen, G., Dong, Z. Y., Hill, D. J., \& Xue, Y. S. (2010). Exploring reliable strategies for defending power systems against targeted attacks. IEEE Transactions on Power Systems, 26(3), 1000-1009.

[3] Hakan, K., \& Seval, F. (2011). CIPP evaluation model scale: development, reliability and validity. Procedia-Social and Behavioral Sciences, 15, 592-599.

[4] Hammond, D., \& Gast, D. L. (2010). Descriptive analysis of single subject research designs: 19832007. Education and Training in Autism and Developmental Disabilities, 187-202.

[5] Ho, W. W., Chen, W. J., Ho, C. K., Lee, M. B., Chen, C. C., \& Chou, F. H. C. (2011). Evaluation of the suicide prevention program in Kaohsiung city, Taiwan, using the CIPP evaluation model. Community mental health journal, 47(5), 542-550.

[6] Rajiani, I., \& Jumbri, I. A. (2011). The cultural ecology of new public management in Indonesia. Journal of Administrative Science, 8(1), 17-31.

[7] Rajiani, I. (2010). Applying Personality Traits to Predict Loyalty and Neglect among Employees of Bank Jatim Located in 10 Big Cities of East Java (Mc Crae's and Hofstede's Theories on the effect of Culture on Personality Revisited). Jurnal Aplikasi Manajemen, 8(3), 617-622.

[8] Riseman, N. (2012). Defending whose country?: Indigenous soldiers in the Pacific war. U of Nebraska Press.

[9] Stufflebeam, D. L., \& Zhang, G. (2017). The CIPP evaluation model: How to evaluate for improvement and accountability. Guilford Publications.

[10] Tunc, F. (2010). Evaluation of an English language teaching program at a public university using the CIPP model. Unpublished Master's Thesis). Middle East Technical University, Ankara.

[11] Zhang, G., Zeller, N., Griffith, R., Metcalf, D., Williams, J., Shea, C., \& Misulis, K. (2011). Using the context, input, process, and product evaluation model (CIPP) as a comprehensive framework to guide the planning, implementation, and assessment of service-learning programs. Journal of Higher Education Outreach and Engagement, 15(4), 57-84.

Citation: Deni Dadang Ahmad Rajab, et.al., “Evaluation of Country Awareness Program Development through Education and Training " International Journal of Managerial Studies and Research (IJMSR), vol 8, no. 7, 2020, pp. 56-63. doi: http:// dx.doi.org/10.20431/2349-0349.0807007.

Copyright: (C) 2020 Authors. This is an open-access article distributed under the terms of the Creative Commons Attribution License, which permits unrestricted use, distribution, and reproduction in any medium, provided the original author and source are credited. 